NBER WORKING PAPER SERIES

INTERNATIONAL POLICY COORDINATION IN A DYNAMIC MACROECONOMIC MODEL

Jeffrey Sachs

Working Paper No. 1166

NATIONAL BUREAU OF ECONOMIC RESEARCH

1050 Massachusetts Avenue

Cambridge MA 02138

July 1983

The research reported here is part of the NBER's research program in International Studies. Any opinions expressed are those of the author and not those of the National Bureau of Economic Research. 
International Policy Coordination in a Dynamic Macroeconomic Mode1

\begin{abstract}
This paper illustrates the role for macroeconomic policy coordination when interdependent economies are pursuing disinflationary policies. Under flexible exchange rates, policy makers have an incentive to reduce inflation by pursuing contractionary policies that yield a currency appreciation. In a Nash, perfect foresight equilibrium, policy authorities in the model pursue contractionary policies to achieve currency appreciation, but these attempts cancel out, with the result that all countries end up pursuing excessively contractionary policies (relative to a symmetric Pareto optimum). The paper presents these results in a two-country, infinite-horizon difference game.
\end{abstract}

Jeffrey Sachs National Bureau of Economic Research 1050 Mass. Ave. Cambridge, MA 02138 (617) $868-3900 \times 356$ 
Introduction

One of the major considerations in the original design of the Bretton Woods system was the control of "beggar-thy-neighbor" exchange rate policies. As the post World War I gold-exchange standard disintegrated in the 1930 s under the weight of world deflation, several countries pursued exchange rate devaluations in the hope of gaining competitive advantages vis-à-vis their trading partners. In the eyes of the Bretton Woods architects, these "competitive devaluations" contributed to the financial turbulence of the 1930 s and the breakdown of the world trading system. Henceforth, countries' exchange rate policies were to be subject to international surveillance, in part to prevent countries from gaining undue economic benefits at the expence of others. This international control was enshrined in Article IV of the International Monetary Fund Articles of Agreement.

With the breakdown of the Bretton Woods par-value system in the ear1y 1970s, the problem of "beggar-thy-neighbor" exchange rate polictes have again come to the fore. But now there is a new twist. As concern shifted from fighting unemployment to fighting inflation, countries have often pursued a policy of exchange rate apprectation as an anti-inflation weapon. A rising exchange rate reduces import prices and hence domestic inflation, with particularly large effects if domestic wages and prices slow down in response to reduced import prices. Just as a competitive depreciation may work in part by exporting unemployment, a "competitive appreciation" may work in part by exporting inflation, thus hindering inflation control in other countries. 
The possibility of beggar-thy-neighbor exchange rate policy is not, in Itself, evidence of a structural problem in the world monetary system. It may be true for example that when one country's beggar-thy-neighbor policles are counteracted by another's, both countries are left better off than they would be in the absence of the policy moves. $1 /$ But as we know from tariff wars, it is possible that both countries are left worse off, even when they each react optimally to the other's policies. $2 /$ A system of rules (or "code of conduct") may well raise welfare in both countries above the levels reached when each country acts in its narrow self-interest, taking the others' policies as given. In technical terms, the cooperative outcome may be Pareto superior to the Nash equilibrium in policies.

The basic result has been known since the important work of Johnson (1953) on tariff wars and Hamada (1974, 1976, and 1979) on monetary policy under fixed exchange rates. Johansen (1982) and Canzoneri and Gray (1982) have applied the argument to the current policy environment, in which supply shocks have worsened inflation and current account balances simultaneously in many economies, causing many countries to pursue beggar-thy-neighbor policies to reduce external deficits and inflation.

This note seeks to add two aspects to the Johansen and CanzoneriGray papers: (1) a particular channel through which policy inefficiencies may arise; and (2) an intertemporal illustration of the coordination problem. On the first point, I stress the aim of policy makers in seeking a strong exchange rate as an anti-inflation device. Each country pursues contractionary policies to strengthen the exchange rate. The policies counteract 
each other; both countries end up with a contraction, but neither succeeds in currency appreciation. The argument is used to illustrate why the supply shocks of 1973 and 1979 in the environment of flexible rates have led to excessive world contraction.

On the second point, almost all illustrations of the problems of exchange rate interaction and coordination have been static, or repeated oneperiod games. (In a very useful recent paper, Miller and Salmon (1983) provide the general solution of the $\mathrm{N}$-player infinite-horizon linear-quadratic differential game, but they must resort to numerical simulation to solve their example. I offer an analytical solution in this paper.) I show here that the arguments about "competitive apprectation" readily extend to a dynamic context. This is a little bit surprising since Buiter and Miller (1982) have pointed out that the inflation gains achieved by a real appreciation must be "given back" at a later date, when the real appreciation unwinds. However, with utility quadratic in inflation and output, policy makers will still choose to take a real apprectation early on when they are trying to reduce a high initial rate of inflation.

Section I presents a static model of competitive appreciation, and Section II considers the dynamic extension. The models are highly stylized to illustrate clearly the Issues at hand; no attempt at generality is made. Some extensions are suggested at the end of the paper.

\section{A Static Model}

Consider two completely symmetrical economfcs. Each produces a 
single final good that is an imperfect substitute for the other in final demand. Let $Q$ and $Q *$ be total output in the home and foreign economies (with "*" signifying foreign), and $\mathrm{P}$ and $\mathrm{P*}$ be output prices in national currencies. $\mathrm{E}$ is the exchange rate, assumed to be floating, (and measured as the domestic currency price of a unit of foreign exchange). For all variables, the lowercase form will represent the logarithm of the upper-case counterpart (e.g. $\mathrm{q}=\ln \mathrm{Q}, \quad \mathrm{p}=\ln \mathrm{P}) ;$ and " ${ }^{\prime}$ will signify change between periods (e.g. $\left.\hat{\mathrm{q}}_{\mathrm{t}}=\mathrm{q}_{\mathrm{t}}-\mathrm{q}_{\mathrm{t}-1}\right)$.

The basic assumption of the model is that domestic growth in excess of foreign growth leads to real exchange rate depreciation:

$$
\left(\hat{\mathrm{q}}_{\mathrm{t}}-\hat{\mathrm{q}}_{\mathrm{t}}^{*}\right)=-\alpha\left(\hat{\mathrm{p}}_{\mathrm{t}}-\hat{\mathrm{e}}_{\mathrm{t}}-\hat{\mathrm{p}}_{\mathrm{t}}^{*}\right) \quad, \quad \alpha>0
$$

Under this assumption, not only high levels of demand, but demand expansion relative to one's trading partner, will have inflationary consequences in the short run. Equation (1) may be justified in several ways, as the basic property is consistent with several models of international macroeconomics. Most simply, we might suppose that the proportion of total world demand spent on domestic goods is a negative function of the relative price $\mathrm{p}-\mathrm{e}-\mathrm{p}^{*}$, so that $\left(\mathrm{q}-\mathrm{q}^{*}\right)=-\xi^{\mathrm{D}}\left(\mathrm{p}-\mathrm{e}-\mathrm{p}^{*}\right)$, where $\xi^{\mathrm{D}}$ is an elasticity of demand. Taking first differences, we arrive at (1). It is possible, however, that domestic fiscal policy (f) can shift the distribution of world demand, say towards the home good, so that (1) would be modified to be

$$
\left(q-q^{*}\right)=-\xi^{D}\left(p-e-p^{*}\right)+\phi\left(f-f^{*}\right)
$$


Implicitly, (I) is more accurate for models in which variations in output depend on monetary policy rather than fiscal policy.

We will assume that each country produces its final output with value added (price $P_{v}$ ) and a traded intermediate input (price $P_{n}$ ), such that

$$
\begin{aligned}
& \hat{p}_{t}=a \hat{p}_{v_{t}}+(1-a) \hat{p}_{n_{t}} \\
& \hat{p}_{t}^{*}=a \hat{p}_{v_{t}}^{*}+(1-a) \hat{p}_{n_{t}}^{*}
\end{aligned}
$$

We will further assume that $P_{v}$ is a fixed markup over the wage, so that

$$
\begin{aligned}
& \hat{p}_{v_{t}}=\hat{w}_{t} \\
& \hat{p}_{v_{t}}^{*}=\hat{w}_{t}^{*}
\end{aligned}
$$

The price of the intermediate input (e.g. oil) is assumed to be fixed in terms of a basket of $Q$ and $Q^{*}$, with weights 0.5 each and real price s:

$$
\hat{p}_{n_{t}}=\hat{s}_{t}+0.5 \hat{p}_{t}+0.5\left(\hat{p}_{t}^{*}+\hat{e}_{t}\right)
$$

Also, since the intermediate input is a pure tradeable good, $\hat{p}_{n}^{*}=\hat{p}_{n}-\hat{e}$. The wage is assumed to be fully indexed to consumer prices $\left(\mathrm{P}_{c}\right)$, though with a one-period lag, and to respond as well to the level of demand ( as measured by q):

$$
\hat{w}_{t}=\hat{p}_{c_{t-1}}+\psi q_{t-1}
$$


Fina11y, consumer prices are taken to be a weighted average of home and foreign final good prices:

$$
\begin{aligned}
& \hat{p}_{c_{t}}=\gamma \hat{p}_{t}+(1-\gamma)\left(\hat{p}_{t}^{*}+\hat{e}_{t}\right) \\
& \hat{p}_{c_{t}}^{*}=\gamma \hat{p}_{t}^{*}+(1-\gamma)\left(\hat{p}_{t}-\hat{e}_{t}\right)
\end{aligned}
$$

When (2) through (6) are combined, we arrive at an "inertial" Phillips curve equation for each country:

$$
\begin{aligned}
& \hat{\mathrm{p}}_{\mathrm{c}_{\mathrm{t}}}=\hat{\mathrm{p}}_{\mathrm{c}_{\mathrm{t}-1}}+\psi \mathrm{q}_{\mathrm{t}-1}+[(1-\mathrm{a}) / \mathrm{a}] \hat{\mathrm{s}}_{\mathrm{t}}-[(1-\gamma)+0.5(1-\mathrm{a}) / \mathrm{a}] \hat{\pi}_{\mathrm{t}} \\
& \hat{\mathrm{p}}_{\mathrm{c}_{\mathrm{t}}}^{*}=\hat{\mathrm{p}}_{\mathrm{c}_{\mathrm{t}-1}}^{*}+\psi \mathrm{q}_{\mathrm{t}-1}^{*}+[(1-\mathrm{a}) / \mathrm{a}] \hat{\mathrm{s}}_{\mathrm{t}}+[(1-\gamma)+0.5(1-\mathrm{a}) / \mathrm{a}] \hat{\pi}_{\mathrm{t}}
\end{aligned}
$$

where $\hat{\pi} \equiv \hat{\mathrm{p}}-\hat{\mathrm{e}}-\hat{\mathrm{p}}^{*}$. We see that a real apprectation at home $\left(\hat{\pi}_{t}>0\right)$ reduces inflation by reducing import prices of foreign final goods and the intermediate input. The real appreciation raises foreign inflation, however, to the extent that it lowers domestic inflation.

By substituting (1) in (7) we may rewrite (7) as

$$
\begin{aligned}
& \left(7^{\prime}\right) \quad \hat{\mathrm{p}}_{\mathrm{c}_{\mathrm{t}}}=\hat{\mathrm{p}}_{\mathrm{c}_{\mathrm{t}-1}}+\beta \mathrm{q}_{\mathrm{t}}+(\psi-\beta) \mathrm{q}_{\mathrm{t}-1}-\beta \hat{\mathrm{q}}_{\mathrm{t}}^{*}+[(1-\mathrm{a}) / \mathrm{a}] \hat{\mathrm{s}}_{\mathrm{t}} \\
& \hat{\mathrm{p}}_{\mathrm{c}_{\mathrm{t}}}^{*}=\hat{\mathrm{p}}_{\mathrm{c}_{\mathrm{t}-1}}^{*}+\beta \mathrm{q}_{\mathrm{t}}^{*}+(\psi-\beta) \mathrm{q}_{\mathrm{t}-1}^{*}-\beta \hat{\mathrm{q}}_{\mathrm{t}}+[(1-\mathrm{a}) / \mathrm{a}] \hat{\mathrm{s}}_{\mathrm{t}}
\end{aligned}
$$

where $\beta=\alpha[(1-\gamma)+0.5(1-a) / a]$. We will see that $\beta$ is a good measure of the degree of interdependence in this model. When $\beta=0$ there are no problems of policy coordination, and as $\beta$ increases, coordination becomes more and more important. 
Consider, now, the one-pertod model in which home and foreign policy makers react to a supply shock, $\hat{s}_{t}>0$. We will assume that the goal of policy is to minimize quadratic loss functions $\Omega$ in $q_{t}$ and $\hat{p}_{c_{t}}$ :

$$
\begin{aligned}
& \Omega=\hat{\mathrm{p}}_{\mathrm{c}_{t}}^{2}+\phi \mathrm{q}_{\mathrm{t}}^{2} \\
& \Omega^{*}=\hat{\mathrm{p}}_{\mathrm{c}_{\mathrm{t}}}^{*}+\phi \mathrm{q}_{\mathrm{t}}^{* 2}
\end{aligned}
$$

In the symmetric cooperative outcome, $q$ and $\mathrm{q}^{*}$ are chosen to minimize the simple average of $\Omega$ and $\Omega^{*}: 0.5\left(\Omega+\Omega^{*}\right)$. The solution to this problem will be Pareto optimal. In the Nash, non-cooperative outcome $q$ is chosen to minimize $\Omega$, taking $\mathrm{q}^{*}$ as given; and $\mathrm{q}^{*}$ is chosen to minimize $\Omega^{*}$, taking $\mathrm{q}$ as given. In general, the Nash non-cooperative outcome will not be Pareto optimal.

Assume that the shock occurs during a perlod of initial equilibrium, with $\hat{\mathrm{p}}_{\mathrm{c}_{\mathrm{t}-1}}=\hat{\mathrm{p}}_{\mathrm{c}_{\mathrm{t}-1}}^{*}=\mathrm{q}_{\mathrm{t}-1}=\mathrm{q}_{\mathrm{t}-1}^{*}=0$. In that case we see from (7) that

$$
\hat{\mathrm{p}}_{\mathrm{c}_{t}}=[(1-\mathrm{a}) / \mathrm{a}] \hat{\mathrm{s}}_{\mathrm{t}}-[(1-\gamma)+0.5(1-\mathrm{a}) / \mathrm{a}] \hat{\pi}_{\mathrm{t}} \cdot
$$

Domestic policy makers can reduce inflation in the period of the shock only by inducing a real appreciation $\left(\hat{\pi}_{t}>0\right)$. Similarly, forelgn policy makers can reduce $\hat{\mathrm{p}}_{\mathrm{c}_{t}}^{*}$ only by inducing $\hat{\pi}_{t}<0$. Thus, a decrease in home inflation comes at the expense of foreign inflation, and vice versa. By adding the Inflation equations we see clearly this negative tradeoff:

$$
\hat{\mathrm{p}}_{\mathrm{c}_{t}}=-\hat{\mathrm{p}}_{\mathrm{c}_{t}}^{*}+2(1-\mathrm{a}) / \mathrm{a} \hat{\mathrm{s}}_{\mathrm{t}}
$$


Because the only anti-inflation policy avallable in this one-period model is beggar-thy-neighbor, the optimal cooperative policy is obvious. Both countries should accept $\hat{\mathrm{p}}_{\mathrm{c}_{t}}=(1-\mathrm{a}) / \mathrm{a} \hat{\mathrm{s}}_{\mathrm{t}}$, and fully accomodate the supp1y shock so that $q_{t}=q_{t}^{*}=0$. The welfare loss in each country is then held to $\Omega=\Omega^{*}=\left[\mathrm{a} /(1-\mathrm{a}) \hat{\mathrm{s}}_{\mathrm{t}}\right]^{2}$.

If the policy-makers follow Nash, non-cooperative strategies, however, both countries will end up with lower levels of social welfare. They will have the same inflation rate ex post, but accompanied by a loss in output. The reason is clear. If the foreign country sets $q_{t}^{*}=0$, the home country has an incentive to set $q_{t}<0$, thereby inducing a real appreciation and exporting inflation.

To show this rigorously, we simply show that at the cooperative equilibrium, $d \Omega / d q_{t}>0$ (for $q_{t}^{*}$ held fixed). In that case the home country has a unilateral incentive to deviate from the cooperative solution. Note that for a given $q_{t}^{*}$, domestic authorities know that a small reduction in output, $\mathrm{dq}_{t}<0$, leads to a fall in domestic inflation given by $\left(7^{i}\right)$ :

$$
d \hat{p}_{c_{t}}=\beta \cdot d_{t}
$$

The welfare effect of such a policy is

$$
\mathrm{d} \Omega=\left(2 \hat{\mathrm{p}}_{\mathrm{c}_{\mathrm{t}}}\right) \mathrm{d} \hat{\mathrm{p}}_{\mathrm{c}_{\mathrm{t}}}+\left(2 \phi \mathrm{q}_{\mathrm{t}}\right) \mathrm{dq}_{\mathrm{t}}=\left(2 \beta \hat{\mathrm{p}}_{\mathrm{c}_{\mathrm{t}}}+2 \phi \mathrm{q}_{\mathrm{t}}\right) \mathrm{dq} \mathrm{q}_{\mathrm{t}}
$$

clearly, for $\hat{\mathrm{p}}_{\mathrm{c}_{\mathrm{t}}}>0$ and $\mathrm{q}_{\mathrm{t}}=0, \mathrm{~d} \Omega / \mathrm{dq}_{\mathrm{t}}>0$.

The Nash equilibrium is found when $\mathrm{d} \Omega / \mathrm{dq}_{\mathrm{t}}=\mathrm{d} \Omega^{*} / \mathrm{dq}_{\mathrm{t}}^{*}=0$. Since the countries are symmetric, both countries will arrive at the same choice of 
output, and $\hat{\pi}_{t}$ will equal zero. At the non-cooperative equilibrium, therefore, $\hat{\mathrm{p}}_{\mathrm{c}_{t}}=\hat{\mathrm{p}}_{\mathrm{c}_{t}}^{*}=(1-\mathrm{a}) / \mathrm{a} \hat{\mathrm{s}}_{\mathrm{t}}$. From the formula for $\mathrm{d} \Omega$, we see that :

$$
\begin{aligned}
& q_{t}^{n c}=-[(1-a) / a \phi] \beta \hat{s}_{t}<0 \\
& q_{t}^{* n c}=-[(1-a) / a \phi] \beta \hat{s}_{t}<0
\end{aligned}
$$

The conclusion is straightforward. In a static model in which inflation is reduced only by exporting it abroad, the cooperative solution is to live with inflation and to stabilize output. If countries act unilaterally, they will each try to export some of the inflation resulting from a supply shock. Output will be reduced in both countries and the attempt to export inflation will cancel out. Thus the Nash equilibrium leaves lower output and unchanged inflation.

Five remarks are in order. First, starting from a point of zero inflation and $q_{t-1}=q_{t-1}^{*}=0$, a negative supply shock $\hat{s}_{t}<0$ will lead to over-expansion and competitive depreciation, as each country tries to stabilize a falling price level.

Second, it is not important that the countries recognize the gaming aspects of policy to arrive at the suboptimal Nash equilibrium. The countries need not be conscious of trying to reduce output relative to their counterpart. What is required is that their "reduced-form estimates" of the inflation unemployment tradeoff yield $\mathrm{dp}_{\mathrm{c}_{t}} / \mathrm{dq}_{\mathrm{t}}=\beta$.

Third, the policy authorities need not see themselves as intentionally reducing $q$ in order to raise $\pi$. They may, more likely, see themselves 
as operating directly on the exchange rate, via a money contraction, with the "unfortunate" side-effect of a reduction in demand and output. The policy actions under discussion are 1ikely to be viewed as "exchange-rate policies" rather than "output-policies."

Fourth, if the economies were operating under a fixed exchange-rate regime, they would likely not have the same freedom of action to pursue the policies under discussion. For example, under a "dollar-standard", in which the home country is free to set $M$, and the other country intervenes in the foreign exchange market until $M^{*}$ is consistent with $M$ and with the par value of the exchange rate, we would have the case that when $q$ is set, $q^{*}$ must be set close to $q$. It is easy to specify a model in which fixed exchange rates force $q=q^{*}$, so that the home monetary authority is led to select the cooperative equilibrium.

Fina11y, even if the authorities are more clever than Nash players, and recognize that output growth in the other country is set according to the choice of output growth domestically, the sub-optimality of the noncooperative outcome will be maintained. Specifically, suppose that each policy authority makes a conjecture of his counterpart's action. The home authority assumes $q_{t}^{*}=\rho\left(q_{t}\right)$ and the foreign authority assumes $q_{t}=\rho\left(q_{t}^{*}\right)$, with $\rho^{\prime}<1$. Then, the output equilibrium will be given as:

$$
\begin{aligned}
& q_{t}=-[(1-a) / a \phi]\left(1-\rho^{\prime}\right) \beta \hat{s}_{t}<0 \\
& \left(q_{t}^{*}\right)=q_{t}
\end{aligned}
$$


The conjectural equilibrium leads to an output loss that is less than the pure Nash case $\left(q^{n c}\right)$, but is sub-optimal nonetheless. Bresnahan (1981) has shown in the quadratic case that the conjectures can be made "rational" in the sense that $\rho^{\prime}$ actually equals $\mathrm{dq}_{\mathrm{t}}^{*} / \mathrm{dq}_{\mathrm{t}}$, where the latter is the slope of the forelgn country's reaction function.

II. The Dynamic Mode1

In this section I verify that the sub-optimality of the Nash equilibrium carries over to a dynamic context. The dynamic model adds two major points of realism. Most important, it allows for a lagged effect of domestic output on home inflation, that is independent of the terms of trade effect. There will now be two ways to reduce inflation: low domestic output, and terms-of-trade improvement. Second, it makes explicit the fact that the terms-of-trade effect represents a temporary gain that is reversed along a complete adjustment path. A country that engineers a terms-of-trade improvement is merely trading off an inflation gain today for an inflation loss in the future, as the terms of trade return to original level. Nonetheless, when faced with high initial rates of inflation (e.g. Inherited from a supply shock), a country will want to make that inter-temporal tradeoff. And for that reason, the non-cooperative equilibrium will still be Pareto Inefficient.

Let us turn to the dynamic model. The price dynamics are st111 given by $\left(7^{\prime}\right)$, as derlved earlier. The soclal welfare functions are now 
written as discounted sums of quadratic loss functions in $q$ and $\hat{p}_{c}$ :

$$
\begin{aligned}
& U=\sum_{i=0}^{\infty}(1+\delta)^{-1}\left[\left(\hat{\mathrm{p}}_{\mathrm{c}_{i}}\right)^{2}+\phi \mathrm{q}_{i}^{2}\right] \\
& \mathrm{U}^{*}=\sum_{i=0}^{\infty}(1+\delta)^{-1}\left[\left(\hat{\mathrm{p}}_{\mathrm{c}_{i}^{*}}\right)^{2}+\phi \mathrm{q}_{i}^{* 2}\right]
\end{aligned}
$$

Pareto-optimal policies are given by pairs of sequences $\left\{q_{i}\right\}_{i=0, \ldots, \infty}$ and $\left\{q_{i}^{*}\right\}_{i=0, \ldots, \infty}$ that minimize a weighted average of $U$ and $U^{*}$ :

$$
\underset{\left\{q_{i}\right\},\left\{q_{i}^{*}\right\}}{\min } \omega U+(1-\omega) U^{*}, \quad 0 \leq \omega \leq 1 \text {. }
$$

Given the symmetry of the model, we will continue to define the cooperative equilibrium as the policy sequences that minimize $0.5 \mathrm{U}+0.5 \mathrm{U}^{*}$. In view of the concavity of $U$ and $U^{*}$ in $q$ and $q^{*}$, and in view of the symmetry of the model, the cooperative equilibrium is characterized by $q_{t}^{c}=q_{t}^{* c}$ for all $t$, a fact which greatly simplifies our analysis.

In the Nash, non-cooperative equilibrium, we suppose that the home authority chooses $\left\{q_{1}^{n c}\right\}$ to minimize $U$, taking $\left\{q_{1}^{* n c}\right\}$ as given; while the foreign policy maker chooses $\left\{q_{i}^{* n c}\right\}$ to minimize $U^{*}$, taking $\left\{q_{i}^{n c}\right\}$ as given. When we turn to the analytical solution to this problem we will find that an equilibrium might not exist, if spillover effects (measured by $\beta$ ) are too large. We will restrict our attention to cases where an eqiflibrium in fact exists.

Let us turn first to the cooperative case. In light of the model's symmetry (making $\mathrm{q}_{i}^{c}=\mathrm{q}_{1}^{{ }^{*} \mathrm{c}}$ ) we see from ( $\left.7^{\prime}\right)$ that:

$$
\hat{\mathrm{p}}_{\mathrm{c}_{\mathrm{t}}}=\hat{\mathrm{p}}_{\mathrm{c}_{\mathrm{t}-1}}+\psi \mathrm{q}_{\mathrm{t}-1}+[(1-\mathrm{a}) / \mathrm{a}] \hat{\mathrm{s}}_{\mathrm{t}}
$$


Minimizing $0.5\left(U+U^{*}\right)$ is tantamount to minimizing $U$, subject to this inflation equation. Details of the optimization are shown in Table 1. At time zero, the entire future planned path of output is selected conditional on $\hat{\mathrm{p}}_{\mathrm{c}-1}$ and the entire anticipated path of future $\hat{\mathrm{s}}_{\mathrm{t}} \cdot$ (For example, an anticipation of a future supply shock causes output to be reduced today, so that inherited inflation is low when the supply shock eventually occurs).

The first order conditions lead to a $2 \times 2$ linear differenceequation system in $p_{t}$ and $\lambda_{t}$, where $\lambda_{t}$ is the shadow welfare loss associated with a one-percentage point increase in inherited inflation $\hat{\mathrm{p}}_{\mathrm{c}_{\mathrm{t}-1}}$ (1.e. it is the co-state variable associated with the inflation equation). The system may be written as:

$$
\begin{aligned}
& {\left[\begin{array}{l}
\hat{\mathrm{p}}_{\mathrm{c}+1} \\
\lambda_{t+1}
\end{array}\right]=\left[\begin{array}{ll}
\left(\psi^{2} / \phi\right)+1 & \psi^{2} / 2 \phi \\
2(1+\delta) & (1+\delta)
\end{array}\right]\left[\begin{array}{l}
\hat{\mathrm{p}}_{\mathrm{t}} \\
\lambda_{\mathrm{t}}
\end{array}\right]+\left[\begin{array}{c}
{[(1-\mathrm{a}) / \mathrm{a}]} \\
0
\end{array}\right] \hat{\mathrm{s}}_{\mathrm{t}+1}} \\
& \text { with } \lim _{t \rightarrow \infty} e^{-\delta t} \lambda_{t}=0
\end{aligned}
$$

It is easy to verify that this equation system is saddlepoint stable, since there is exactly one efgenvalue of the transition matrix with absolute value greater than $1.0 . \underline{3}$ Let the characteristic roots to the matrix in (12) be $\mathrm{v}_{1}^{\mathrm{c}}$ and $\mathrm{v}_{2}^{\mathrm{c}}$, where $\left|\mathrm{v}_{1}^{\mathrm{c}}\right|<1$ and $\left|\mathrm{v}_{2}^{\mathrm{c}}\right|>1$. In fact $0<\mathrm{v}_{1}^{\mathrm{c}}<1$ and $\mathrm{v}_{2}^{\mathrm{c}}>1$ (see footnote 3). Then, the solution to (12), due to Blanchard and Kahn (1980), is found to be: 


\section{TABLE 1}

The Cooperative Solution in the Two-Country Dynamic Game

\section{A. Minimization Problem}

(1)

$$
\begin{aligned}
&\left.\min _{t}\right\}_{t=0,1, \ldots} \sum_{t=0}^{\infty}(1-\delta)^{-t}\left[\left(\hat{p}_{c_{t}}\right)^{2}+\phi\left(q_{t}\right)^{2}\right] \\
& \text { s.t. } \hat{p}_{-1} \text { given; } q_{-1}=0 \\
& \hat{p}_{c_{t}}=\hat{p}_{c_{t-1}}+\psi q_{t-1}+[(1-a) / a] \hat{s}_{t}
\end{aligned}
$$

$$
\left\{\mathrm{q}_{\mathrm{t}}^{*}\right\}=\left\{\mathrm{q}_{\mathrm{t}}\right\}, \mathbf{v}_{\mathrm{t}} \text {, by symmetry }
$$

B. Lagrangian

$$
L=\sum_{t=0}^{\infty}(1+\delta)^{-t}\left\{\left[\left(\hat{p}_{c_{t}}\right)^{2}+\phi\left(q_{t}\right)^{2}\right]+\lambda_{t}\left[\hat{p}_{c_{t}}-\hat{p}_{c_{t-1}}-\psi q_{t-1}-[(1-a) / a] \hat{s}_{t}\right]\right\}
$$

c. First-0rder Conditions

$$
\partial \mathrm{L} / \partial \hat{\mathrm{p}}_{\mathrm{c}_{\mathrm{t}}}=0 \Rightarrow \lambda_{\mathrm{t}+1}=2(1+\delta) \hat{\mathrm{p}}_{\mathrm{c}_{\mathrm{t}}}+(1+\delta)_{\mathrm{t}}
$$

$$
\partial \mathrm{L} / \partial \mathrm{q}_{\mathrm{t}}=0 \Rightarrow \mathrm{q}_{\mathrm{t}}=(1 / 2 \phi) \lambda_{t+1} \psi /(1+\delta)
$$

(3)

$$
\partial \mathrm{L} / \partial \lambda_{t}=0 \Rightarrow \hat{\mathrm{p}}_{\mathrm{c}_{t}}=\hat{\mathrm{p}}_{\mathrm{c}_{t-1}}+\psi \mathrm{q}_{\mathrm{t}-1}+[(1-\mathrm{a}) / \mathrm{a}] \hat{\mathrm{s}}
$$

(4)

$$
\lim _{t \rightarrow \infty}(1+\delta)^{-t} \lambda_{t}=0
$$


(13)

$$
\begin{gathered}
\left(\hat{p}_{c_{t}}\right)^{c}=v_{1}^{c}\left(\hat{p}_{c_{t-1}}\right)^{c}+(1-a) / a \hat{s}_{t}+\left\{\left[v_{1}^{c}-\left(1+\psi^{2} / \phi\right)\right] v_{1}^{c}\right. \\
\left.\quad-\left(\psi^{2} / 2 \phi\right) v_{2}^{c}\right\} \cdot \sum_{i=0}^{\infty}\left(\hat{s}_{t+1} / v_{2}^{c}\right) \\
\left(\hat{q}_{t}^{t}\right)=(1 / \psi)\left(\hat{p}_{c_{t+1}}^{c}-\hat{p}_{c_{t}}^{c}-[(1-a) / a] \hat{s}_{t+1}\right) \\
\left(\hat{p}_{c}^{*}\right)^{c}=\left(\hat{p}_{c_{t}}\right)^{c}, \forall_{t \geq 0} \\
q_{t}^{*}=q_{t}, v_{t \geq 0}
\end{gathered}
$$

where:

$$
\begin{aligned}
& v_{1}^{c}=\left[2+\delta+\psi^{2} / \phi\right] / 2-\left[\left(\delta+\psi^{2} / \phi\right)^{2}+4 \psi^{2} / \phi\right]^{1 / 2} / 2 \\
& v_{2}^{c}=\left[2+\delta+\psi^{2} / \phi\right] / 2+\left[\left(\delta+\psi^{2} / \phi\right)^{2}+4 \psi^{2} / \phi\right]^{1 / 2} / 2
\end{aligned}
$$

Note that current inflation is a function of discounted values of future, anticipated supply shocks, as we11 as lagged inflation.

To take a simple case, suppose that a one-time rise in $\mathrm{S}$ occurs at $t=0$, so that $p_{c_{0}}>0$, and that $\hat{s}_{t}$ is equal to zero for all $t>0$. From (13) we see that the expression for inflation simplifies to:

$$
\left(\hat{\mathrm{p}}_{c_{t}}\right)^{\mathrm{c}}=\mathrm{v}_{1}^{\mathrm{c}}\left(\hat{\mathrm{p}}_{\mathrm{c}_{t-1}}\right)^{\mathrm{c}} \quad \nabla_{t \geq 1}
$$

That is, the optimal policy is to reduce inflation at a geometric rate, given by $v_{1}^{c}$. Output is given by:

$$
q_{t}^{c}=-(1 / \psi)\left(1-v_{1}^{c}\right)\left(\hat{p}_{c_{t}}\right)^{c}
$$


Thus, output may be described as "1eaning against the wind."

The calculation of the non-cooperative equilibrium is shown in Table 2. As in the cooperative equilibrium, symmetry of the model ensures that $q_{t}^{n c}=q_{t}^{* n c}$, and $\hat{\pi}_{t}=0$. But while in the cooperative case the constraint $\hat{\pi}_{t}=0$ was substituted into the inflation equation before the constrained optimization was performed, in the Nash equilibrium each policymaker acts as if he can influence $\hat{\pi}_{t}$, even though $\hat{\pi}_{t}=0$ will result in equilibrium. Once again the optimization problem yeilds a $2 \times 2$ ineardifference-equation system, this time of the form:

$$
\begin{gathered}
{\left[\begin{array}{l}
\hat{\mathrm{p}}_{\mathrm{c}_{\mathrm{t}+1}} \\
\lambda_{\mathrm{t}+1}
\end{array}\right]=\left[\begin{array}{cc}
1+\psi(\psi-\beta) / \phi & \psi^{2} / 2 \phi \\
2(1+\delta) & (1+\delta)
\end{array}\right]\left[\begin{array}{l}
\hat{\mathrm{p}}_{\mathrm{t}} \\
\lambda_{\mathrm{t}}
\end{array}\right]+\left[\begin{array}{c}
{[(1-\mathrm{a}) / \mathrm{a}]} \\
0
\end{array}\right] \hat{\mathrm{s}}_{\mathrm{t}+1}} \\
\text { with } \lim _{\mathrm{t} \rightarrow \infty}(1+\delta)^{-\mathrm{t}} \lambda_{t}=0
\end{gathered}
$$

Note that when $\beta=0,(14)$ reduces to the cooperative case in (12).

For low values of $\beta$, the system in (14) displays saddlepoint stab11ity, with $0<v_{1}^{n c}<1$, and $v_{2}^{\text {nc }}>1$. The stable root is positive. For intermediate values of $\beta$, we again find saddlepoint stability, but now with $-1<v_{1}^{n c}<0$, and $v_{2}^{n c}>1$. For high values of $\beta$, the system is globally unstable, with $v_{1}^{n c}<-1.4$ The unstable case, and the case $-1<v_{1}^{n c}<0$, are not realistic or economically interesting (for $v_{1}^{\text {nc }}<0$, the economies oscillate period to period between negative and positive inflation rates) so 


\section{TABLE 2}

The Non-Cooperative Solution in the Two-Country Dynamic Game

A. Minimization Problem

(1)

$$
\begin{aligned}
& \left.\min _{t}\right\}_{t=0,1, \ldots}-\sum_{t=0}^{\infty}(1+\delta)^{-t}\left[\left(\hat{p}_{c_{t}}\right)^{2}+\phi\left(q_{t}\right)^{2}\right] \\
& \text { s.t. } \quad \hat{p}_{c-1} \text { given; } q_{-1}=0 \\
& \quad \hat{p}_{c_{t}}=\hat{p}_{c}+\psi q_{t-1}+[(1-a) / a] \hat{s}_{t}+\beta\left(\hat{q}_{t}-\hat{q}_{t}^{*}\right) \\
& \left\{q_{t}^{*}\right\} t=0,1, \ldots \\
& \left\{q_{t}^{*}\right\}=\left\{q_{t}\right\}, \forall{ }_{t}, \text { by symmetry }
\end{aligned}
$$

(2)

B. Lagrangian

$$
\begin{gathered}
L=-\sum_{t=0}^{\infty}(1+\delta)^{-t}\left\{\left[\left(\hat{p}_{c_{t}}\right)^{2}+\phi\left(q_{t}\right)^{2}\right]+\lambda_{t}\left[\hat{p}_{c_{t}}-\hat{p}_{c_{t-1}}-\psi q_{t-1}-[(1-a) / a] \hat{s}_{t}\right.\right. \\
\left.\left.-\beta\left(\hat{q}_{t}-\hat{q}_{t-1}^{*}\right)\right]\right\}
\end{gathered}
$$

C. First-Order Conditions

(1)

$$
\partial \mathrm{L} / \partial \hat{\mathrm{p}}_{\mathrm{c}_{t}}=0 \Rightarrow \lambda_{t+1}=2(1+\delta) \hat{\mathrm{p}}_{\mathrm{c}_{t}}+(1+\delta) \lambda_{t}
$$

$$
\partial \mathrm{L} / \partial \mathrm{q}_{\mathrm{t}}=0 \Rightarrow(1 / 2 \phi)\left\{\lambda_{t+1} \psi /(1+\delta)-\left[\beta \lambda_{t}-\beta \lambda_{t+1} /(1+\delta)\right]\right\}
$$

$$
\hat{\mathrm{p}}_{c_{t}}=\hat{\mathrm{p}}_{c_{t-1}}+\psi \mathrm{q}_{\mathrm{t}-1}+[(1-\mathrm{a}) / \mathrm{a}] \hat{\mathrm{s}}_{\mathrm{t}}+\beta\left(\hat{\mathrm{q}}_{\mathrm{t}}-\hat{\mathrm{q}}_{\mathrm{t}}^{*}\right)
$$

(5) $\quad \lim _{t \rightarrow \infty}(1+\delta)^{-t} \lambda_{t}=0$ 
we now confine our attention to the case where $0<v_{1}^{\text {nc }}<1$. The condition on $\beta$ is $\beta<\phi / \psi$, (see footnote 4 ).

The optimal non-cooperative paths of $\hat{\mathrm{p}}_{\mathrm{c}_{t}}$ and $\hat{\mathrm{q}}_{t}$ are found to be:

$$
\begin{aligned}
& \left(\hat{p}_{c_{t}}\right)^{n c}=v_{1}^{n c} \hat{p}_{c_{t-1}}+[(1-a) / a] \hat{s}_{t}+\left\{v_{1}^{n c}-[1+\psi(\psi-\beta) \phi] v_{1}^{n c}\right. \\
& \left.\quad-\left(\psi^{2} / 2 \phi\right) v_{2}^{n c}\right\} \cdot \sum_{i=0}^{\infty}\left[\hat{s}_{t+1} /\left(v_{2}^{n c}\right)^{i+1}\right] \\
& \left(q_{t}\right)^{n c}=(1 / \psi)\left(\hat{p}_{c_{t+1}}-\hat{p}_{c_{t}}-[(1-a) / a] \hat{s}_{t+1}\right) \\
& \left(\hat{p}_{c_{t}}^{*}\right)^{n c}=\left(\hat{p}_{c}\right)^{n c}, v_{t} \\
& \left(q_{t}\right)^{n c}=\left(q_{t}\right)^{n c}, v_{t}
\end{aligned}
$$

where:

$$
\begin{aligned}
& \mathrm{v}_{1}^{\mathrm{nc}}=[2+\delta+\psi(\psi-\beta) / \phi] / 2-\left[\{\delta+[\psi(\psi-\beta) / \phi]\}^{2}+4 \psi^{2} / \phi+4 \delta \psi \beta / \phi\right]^{1 / 2} / 2 \\
& \mathrm{v}_{2}^{\mathrm{nc}}=[2+\delta+\psi(\psi-\beta) / \phi] / 2+\left[\left\{\delta+[\psi(\psi-\beta) / \phi]^{2}+4 \psi^{2} / \phi+4 \delta \psi \beta / \phi\right]^{1 / 2} / 2\right.
\end{aligned}
$$

Once again, consider the case when $\hat{s}_{t}=0$ for all $t>0$, and $\hat{s}_{0}>0$. In Nash equilibrium, policy makers again reduce inflation at a constant geometric rate, given now by $v_{1}^{\text {nc }}$. Output is again "leaning against the wind" with $q_{t}^{n c}=-(1 / \psi)\left(1-v_{1}^{n c}\right) \hat{p}_{c}^{n c}$.

The key result of this section is that $v_{1}^{c}>v_{1}^{n c}$, in other words that the cooperative solution is to reduce inherited inflation more slowly 
than in the non-cooperative case. $\underline{5}$ once again, when countries act independently, they race to be the first to contract when they have inherited a high initial rate of inflation. It is easy to show that $v_{1}^{c}-v_{1}^{n c}$ depends precisely upon the potential gain from a terms-of-trade improvement, as measured by $\beta$. When this measure equals zero, $v_{1}^{c}=v_{1}^{n c}$; as this measure increases, $v_{1}^{c}-v_{1}^{n c}$ increases.

we have that (for $\hat{s}_{t}=0$ )

$$
\text { Since } q_{t}^{c}=-(1 / \psi)\left(1-v_{1}^{c}\right) \hat{p}_{c_{t}} \text { and } p_{c_{t}}^{c}=v_{1}^{c} p_{c_{t-1}}^{c} \text {, }
$$

$$
q_{t}^{c}=-(1 / \psi)\left(1-v_{1}^{c}\right)\left(v_{1}^{c}\right)^{t} \hat{p}_{c_{0}} \quad v_{t \geq 0}
$$

Similarly,

$$
q_{t}^{n c}=-(1 / \psi)\left(1-v_{1}^{n c}\right)\left(v_{1}^{n c}\right)^{t} \hat{p}_{c_{0}} \quad \forall_{t \geq 0}
$$

It is easy to see that there exists a period $T$, such that for $0<t<T$, $0>q_{t}^{c}>q_{t}^{n c}$; and for $t>T, 0>q_{t}^{n c}>q_{t}^{c}$. Also, $\underset{t \rightarrow \infty}{\lim } q_{t}^{n c}=q_{t}^{c}=0$.

Thus, the non-cooperative policy involves larger output losses in the adjustment process, and smaller output losses later on. The total loss of output, measured as $\sum_{t=0}^{\infty} q_{t}$ is exactly the same in both cases. $6 /$

Figure 1 shows the time paths of $q^{\text {nc }}$ and $q^{c}$. The curves cross at time $T$, as defined above. (Strictly, they cross in the interval $(T-1, T+1)$. )

By construction, the cooperative solution is Pareto optimal, and Pareto dominates the non-cooperative solution. By substituting the equations for inflation and output back into the utility functions, we may directly verify that $U^{c}>U^{\text {nc }}$. 


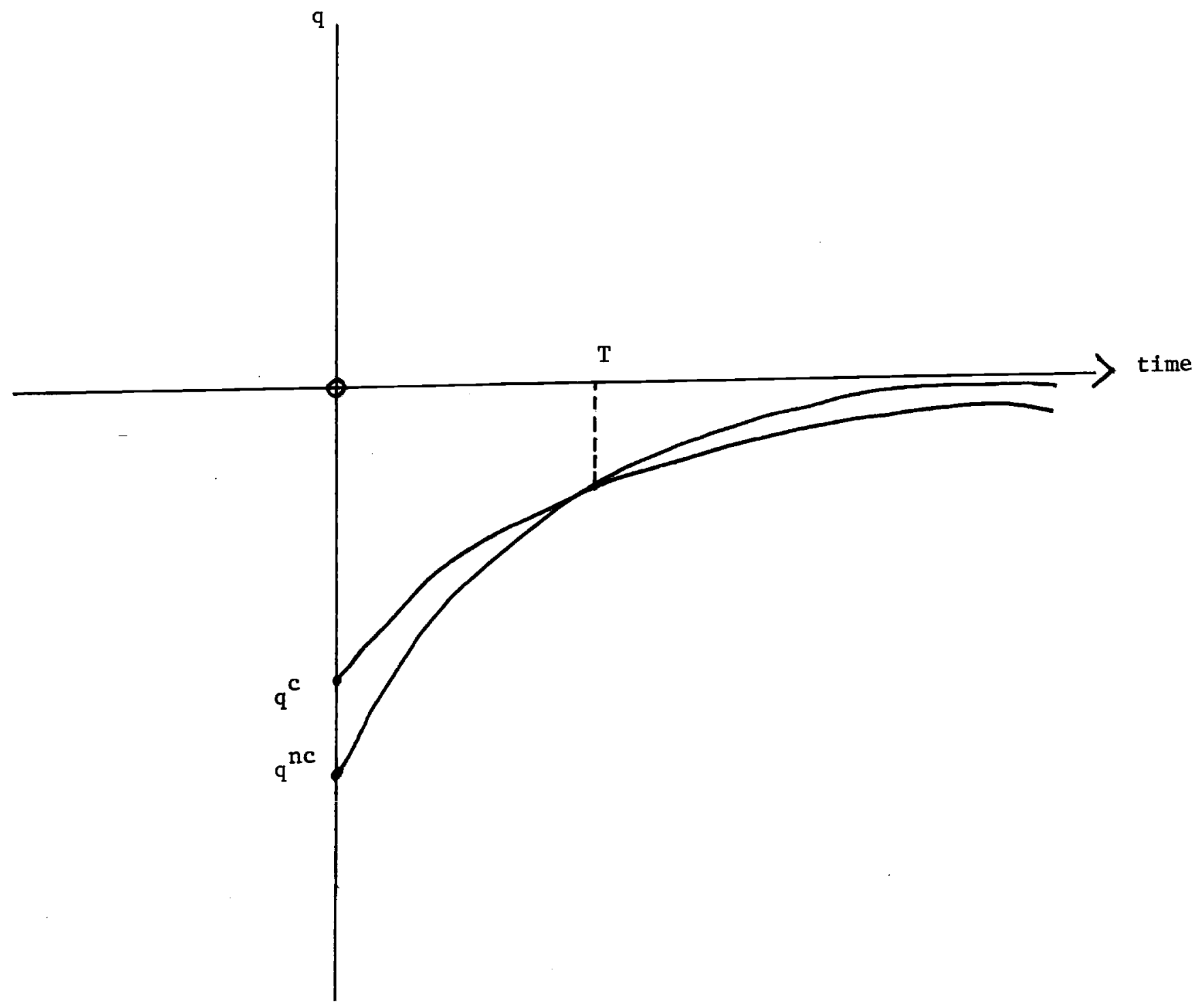

FIGURE 1. Adjustment Paths of Output, Cooperative $\left(q^{c}\right)$ and Non-Cooperative $\left(q^{\text {nc }}\right)$ Cases. 


\section{Conclusions}

We have illustrated in this paper that non-cooperative policy making in a two-country model with flexible exchange rates is likely to result in Pareto inefficient equilibria. In the specific, stylized model under investigation here, the source of inefficiency is that each country attempts to manipulate the exchange rate to its own advantage in fighting inflation, though in equilibrium these attempts cancel out and prove selfdefeating.

Other papers, cited in the introduction, have investigated other possible courses of inefficiency. One novelty of this paper is the extension of the policy game to an intertemporal environment.

There are several extensions of this model that should prove worthwhile. First, using equations (13) and (15), we could discuss the possible inefficiencies in response to anticipated future changes in the global environment. Second, we might usefully extend the model to nonsymmetrical cases, and consider the effects on equilibrium if one country acts as a Stackelberg leader vis-à-vis the other. Third, we should spell out the macroeconomic model with more care, to see whether the introduction of several policy instruments in each country could alter the basic effects observed here. Fourth, we might imbed the two countries in a specific and detailed institutional environment with respect to exchange rate rules, to see how changes in global rules affects the efficiency of equilibrium (e.g. compare a gold standard, dollar-exchange standard, and freely floating exchange regime). Finally, we might usefully introduce a stochastic structure 
to see how the relative prevalence of various types of disturbances affects the desirability of alternative "rules of the game." 


\section{LIST OF REFERENCES}

Blanchard, O. J. and C. M. Kahn (1980), "The Solution of Linear Difference Mode1s Under Rational Expectations," Econometrica, July 1980, 1305-1312.

Bresnahan, T. (1981), "Duopoly Models with Consistent Conjectures," American Economic Review, Vol. 71, No. 5, December, 934-945.

Buiter, W. H. and M. H. Miller (1981), "Monetary Policy and International Competitiveness," Oxford Economic Papers, Vo1. 33, 143-175, Supplement. Canzoner1, M. B. and J. A. Gray (1983), "Two Essays on Monetary Policy in in Interdependent World," International Finance Discussion Papers, No. 219, February.

Hamada, K. (1974), "Alternative Exchange Rate Systems and the Interdependence of Monetary Policies," In Robert A. Aliber (ed.) National Monetary Policies and the International Financial System, (Chicago: University of Chicago Press), 13-33.

, (1976), "A Strategic Mode1 of Monetary Interdependence," Journal of Policital Economy, Vo1. 84, August, 677-700.

, (1979), "Macroeconomic Strategy and Coordination Under Alternative Exchange Rates," in Rudiger Dornburch and Jacob Frenkel (eds.) International Economic Policy, (Baltimore: Johns Hopkins Press), 292-324.

Johansen, L. (1982), "The Possibility of an International Equilibrium with Low Levels of Activity," Journal of International Economics Johnson, H. (1953), "Optimum Tariffs and Retaliation," The Review of Economic Studies, 21, 142-153. 


\section{FOOTNOTES}

1. In the Great Depression, for example, a series of "competitive devaluations" in all countries could have raised the world money stock to the advantage of all of the countries.

2. See the seminal contribution of H. Johnson (1953).

3. Let $\theta_{i}=v_{i}-1$, where $v_{i}$ is a characteristic root of (12). According to the characteristic equation for $(12), \theta_{i}$ is a root of the equation:

$$
\theta_{i}^{2}-\left[\delta+\psi^{2} / \phi\right] \theta_{i}-\psi^{2} / \phi=0
$$

By Descartes' law of signs, there are two values of $\theta_{i}$, one positive and one negative. Also, it is clear that the negative value of $\theta_{i}$ must be $-1<\theta_{i}<0$, since the equation may be rewritten as

$$
\theta_{i}^{2}-\delta \theta_{i}-\left(1+\theta_{i}\right) \psi^{2} / \phi=0
$$

for which the LHS is always the positive for $\theta_{1}<-1$. Thus, since $v_{1}=\theta_{1}+1$, there is one root $v_{i}$ that is $0<v_{i}<1$ (corresponding to $-1<\theta_{i}<0$ ) and one root $v_{i}$ that is $v_{i}>1$ (corresponding to $\theta_{i}>0$ ).

4. The conditions on $\beta$ are derived as in footnote 3 . Again, let $\theta_{i}=v_{i}-1$. Then, $\theta_{i}$ is a root of the equation

$$
\theta_{i}^{2}-[\delta+\psi(\psi-\beta) / \phi] \theta_{i}-\left[\delta \psi \beta / \phi+\psi^{2} / \phi\right]=0
$$

Again, there is one change of sign, so that one value of $\theta_{1}$ is positive and the other is negative. The negative root is greater than -1 if and only if $\beta<\phi / \psi$, which we assume. The negative root is between -1 and -2 (inclusive) if and on $1 y$ if $\phi / \psi \leq \beta \leq\left(4 \phi+2 \hat{\delta} \phi+\dot{\psi}^{2}\right) / \psi(2+\delta)$. Once we assume $\beta<\phi / \psi$, then the $v_{i}$ corresponding to the negative $\theta_{i}$ is between 0 and 1 , and the $v_{i}$ corresponding to the positive $\theta_{i}$ is greater than 1 . We write:

$$
0<v_{i}^{n c}<1<v_{2}^{n c} \text {. }
$$


5. From the definitions of $v_{1}^{c}$ in (12) and $v_{1}^{n c}$ in (15), we see that $v_{1}^{c}=v_{1}^{n c}$ when $\beta=0$. It is also true (see below) that $\partial v_{1}^{\mathrm{nc}} / \partial \beta<0$ while $\partial v_{1}^{\mathrm{c}} / \partial \beta=0$. Thus, for positive $\beta, v_{1}^{c}>v_{1}^{\text {nc }}$. Also, it follows that $\partial\left(v_{1}^{c}-v_{1}^{n c}\right) / \partial \beta>0$. To show that $\partial v_{1}^{n c} / \partial \beta<0$, first define

$$
\Sigma=\left[\{\delta+[\psi(\psi-\beta) / \phi]\}^{2}+4 \psi^{2} / \phi+4 \delta \psi \beta / \phi\right]^{1 / 2},
$$

so that $v_{1}^{n c}=[2+\delta+\psi(\psi-\beta) / \phi] / 2-\Sigma / 2$.

Then, by direct computation:

$$
\partial \mathrm{v}_{1}^{\mathrm{nc}} / \partial \beta=-(\psi / 2 \phi)\{1+[\delta-\psi(\psi-\beta) / \phi] / \Sigma\} \text {. }
$$

It is easy to show that $[\delta-\psi(\psi-\beta) / \phi]^{2} / \Sigma^{2}<1$, so that $\partial v_{1}^{\text {nc }} / \partial \beta$ must be negative.

6. In both the nc and c cases, an initial level of inflation $\hat{\mathrm{p}}_{\mathrm{c}_{\mathrm{o}}}$ is reduced to zero over time (with $\lim _{t \rightarrow \infty} \hat{p}_{c_{t}}=0$ ). For $\hat{s}_{t}=0$ and $q_{t}=q_{t}^{*}$, the inflation rate is governed by

$$
\hat{\mathrm{p}}_{\mathrm{c}_{t+1}}=\psi \sum_{i=0}^{t} \mathrm{q}_{i}+\hat{\mathrm{p}}_{\mathrm{c}_{\mathrm{o}}} \text {, }
$$

so that

$$
\sum_{i=0}^{t} q_{t}=1 / \psi\left(\hat{p}_{c_{t+1}}-\hat{p}_{c_{o}}\right) .
$$

Taking limits of both sides,

$$
\sum_{i=0}^{\infty} q_{t}=-\hat{p}_{c_{0}} / \psi
$$

Thus, the total amount of foregone output is set by the initial inflation rate. The nc path and the $c$ path entail an identical level of total output loss. 